\title{
Bedakvilino ir delamanido vartojimas vaistams atspariai tuberkuliozei gydyti. Kokių šalutinių poveikių galima tikètis?
}

\author{
DRUG-RESISTANT TUBERCULOSIS TREATMENT WITH BEDAQUILINE AND \\ DELAMANID. WHAT ADVERSE EVENTS ARE TO BE EXPECTED?
}

\author{
IEVA GAUDIEŠIŪTĖ, SKAIDRIUS MILIAUSKAS \\ LSMU MA Pulmonologijos klinika
}

\begin{abstract}
Santrauka. Tyrimo tikslas. Ištirti, ar naujųų medikamentų nuo tuberkuliozės (TB) - bedakvilino (BDQ) ir delamanido (DLM) vartojimas klinikinèje praktikoje yra saugus. Tyrimo metodai. Atlikta retrospektyvioji 32 vaistams atsparia (VA) TB sergančių pacientų, gydytų BDQ ir (arba) DLM nuo 2016 m. antrojo pusmečio iki 2019 m. pirmojo ketvirčio pabaigos Lietuvos sveikatos mokslų universiteto ligoninès Kauno klinikų filialo Romainių TB ligoninės Rezistentinès TB skyriuje, ligos istorijų analizė. Vertinti tiriamųjų duomenys bei naujųjų medikamentų nuo TB sukelti šalutiniai poveikiai. Rezultatai. Didžioji dalis tiriamųjų buvo santykinai jauno amžiaus (mediana - 50 metų) vyrai. 59,38 proc. pacientų buvo piktnaudžiaujantys alkoholiu. 56,3 proc. pacientų, gydytų naujaisiais vaistais nuo TB, sirgo ypač vaistams atsparia TB. Dažniausiai radiologiškai rastas abipusis plaučių pažeidimas (68,75 proc.). Pusei tiriamųjų pasireiškẻ bent vienas galimas šalutinis poveikis. Dažniausi galimi šalutiniai poveikiai: QTc intervalo prailgejimas, išbėrimas, pykinimas arba vėmimas. Rečiau pasireiške periferinè neuropatija, viduriavimas, širdies plakimo pojūtis. Dèl kliniškai reikšmingų pokyčių elektrokardiogramoje vienam pacientui nutrauktas gydymas DLM. Trimis (9,38 proc.) atvejais neabejota, jog šalutini poveikị sukèlè BDQ arba DLM. Gydymo metu statistiškai reikšmingo ryšio tarp amžiaus, lyties bei alkoholio vartojimo ir galimų šalutinių poveikių pasireiškimo nenustatyta $(p>0,05)$. Statistiškai reikšmingo QTc intervalo prailgejimo ryšio su amžiumi bei lytimi taip pat nepavyko nustatyti $(p>0,05)$, tačiau tai imtyje buvo būdinga tik vyrams. Išvados. Gydymas naujaisiais prieštuberkulioziniais vaistais yra pakankamai saugus. Siekiant nustatyti ịvairių veiksnių įtaką šalutinių poveikių pasireiškimui, tikslinga atlikti tyrimą su didesne imtimi.

Reikšminiai žodžiai: bedakvilinas, delamanidas, vaistams atspari tuberkuliozè, šalutiniai poveikiai.

Summary. The aim. To determine if treatment regimens including new antituberculous drugs bedaquiline (BDQ) and delamanid (DLM) are clinically safe. Methods. A retrospective analysis of 32 drug-resistant tuberculosis (DR-TB) patients who were treated with BDQ and/or DLM in Lithuanian University of Health Sciences Kauno klinikos affiliated hospital Romaniai Hospital of Tuberculosis Department of Resistant TB was performed. The features of patients and possible adverse events (AEs) of new antituberculous drugs were evaluated. Results. The majority of patients were relatively young men (mode - 50 years). 59.38\% of patients were excessive alcohol users. $56.3 \%$ of patients which were treated with these new antituberculous drugs had extensively drug-resistant TB. Bilateral involvement was the most common radiological finding (68.75\%). Half of the patients had at least 1 of the possible AEs. The most common possible AEs were QTc interval prolongation, skin rash, nausea/vomiting, while peripheral neuropathy, diarrhea and palpitations were rarer. One patient had to stop treatment because of clinically significant changes in electrocardiogram. 3 (9.38\%) cases of AEs were undoubtedly caused by new antituberculous drugs (BDQ and DLM). There was no statistically significant relation between age, sex, alcohol consumption and possible AEs $(\mathrm{p}>0.05)$. There was no statistically significant relation between age, sex and QTc interval prolongation $(p>0.05)$ either. However, in our study QTc interval prolongation occurred only in men. Conclusion. After a careful consideration of the research results it was concluded that treatment with these new antituberculous drugs is sufficiently safe. However, in order to assess how various factors impact the manifestation of AEs, studies with larger sample size should be performed.
\end{abstract}

Keywords: bedaquiline, delamanid, drug-resistant tuberculosis, adverse events.

\section{IVADAS}

2019 m. publikuotose Pasaulio sveikatos organizacijos vaistams atsparios (VA) tuberkuliozès (TB) gydymo rekomendacijose rasta esminių skirtumų, palyginus su 2016 m. gairèmis. Tarp pirmojo pasirinkimo medikamentų dominuoja naujieji vaistai nuo TB: bedakvilinas (BDQ) ir delamanidas (DLM) bei atnaujinto vartojimo linezolidas (LZD) ir klofazaminas (CFZ), kurie iki šiol buvo skiriami, jei nepavykdavo sudaryti pakankamai veiksmingu VA-TB gydymo schemų, derinant antros eilès vaistus nuo TB: fluorochinolonus (FQ), aminoglikozidus (kapreomiciną - $\mathrm{Cm}$, kanamiciną - Km, amikaciną - Am), tioamidus (etionamidą - ETH, protionamidą - PTH), paraaminosalicilo rūgštị (PASR), 


\section{Moksliniai darbai ir apžvalgos}

cikloseriną (Cks). Kadangi Lietuvoje VA-TB paplitimas yra vienas didžiausių pasaulyje (20 proc. visų TB atvejų sudaro DVA-TB), itin svarbu mūsų šalyje užtikrinti prieinamą veiksmingiausią gydymą [1].

Tam, kad BDQ ir DLM skyrimas būtų pagrịstas, pasaulyje vykdomi tyrimai, pateikiantys įrodymų apie šių medikamentų saugumą ir veiksmingumą. $2017 \mathrm{~m}$. publikuotame daugiacentriame tyrime nurodyta, jog iš 428 VA-TB sirgusių ir BDQ gydytų pacientų 5,8 proc. atvejų gydymas buvo sustabdytas dẻl galimų šio vaisto šalutinių poveikių [2]. Kadangi žinoma, jog vienas grèsmingiausių BDQ ir DLM šalutinių poveikių yra širdies aritmijos, sukeliamas QTc intervalo prailgejimo, atliekami tyrimai, kuriuose vertinamas šio poveikio paplitimas ir klinikinis reikšmingumas. Tyrime, atliktame Pietų Korèjoje, kurio imtis 61 pacientas, nurodoma, jog keturiems pacientams, gydytiems BDQ ir (arba) DLM, gydymas buvo sustabdytas dèl didelio QTc intervalo prailgejjimo [3]. Indijos tyrèjai pastebejjo, kad iš 53 pacientų, gydytų BDQ ir DLM deriniu vienu metu, QTc intervalo prailgejjimas daugiau nei $500 \mathrm{~ms}$ nustatytas vienam pacientui [4]. BDQ ir DLM turi ir kitų, mažiau pavojingų, tačiau diskomfortą keliančių šalutinių reiškinių - tai daugeliui vaistų būdingi pykinimas, vėmimas, viduriavimas, odos reakcijos, periferinès neuropatijos, sąnarių skausmas, kurie neretai skatina pacientus atsisakyti gydymo naujaisiais medikamentais [5]. 2019 m. publikuoti didelès imties (658 vaistams atsparia TB sergantys pacientai) 26 pasaulio šalyse vykdyto klinikinio tyrimo rezultatai, kuriuose skelbiama, kad dèl sunkių BDQ ir DLM šalutinių poveikių gydymas šiais vaistais nutrauktas buvo atitinkamai - 0,35 (2 iš 577) ir 0,8 proc. (1 iš 121) atvejų [6].

Šis tyrimas atliktas, siekiant išsiaiškinti ir pasidalyti, su kokiais galimais šalutiniais poveikiais, skiriant naujuosius prieštuberkuliozinius vaistus, susidūrè Lietuvos sveikatos mokslų universiteto ligoninès Kauno klinikų (toliau - Kauno klinikos) filialo Romainių TB ligoninès gydytojai pirmus trejus metus gydydami VA-TB sergančius pacientus schemomis su BDQ ir DLM.

\section{TYRIMO METODAI}

Atliktas retrospektyvusis stebėsenos tyrimas, kurio metu buvo vertinti stacionarinių ligos istorijų įrašai apie pacientų būklę bei atliktus tyrimus, nenaudojant duomenų, galinčių atskleisti pacientų tapatybes. Nagrinèti visų 32 VA-TB sergančių pacientų, gydytų BDQ ir (arba) DLM nuo $2016 \mathrm{~m}$. antrojo pusmečio iki 2019 m. pirmojo ketvirčio pabaigos Kauno klinikų filialo Romainių TB ligoninès Rezistentinès TB skyriuje, ligos istorijų duomenys. Atlikta medicininių dokumentų analizè, vertintas tiriamųjų pasiskirstymas pagal lytị, amžių, atsparumo vaistams formą (daugeliui vaistų atspari TB - DVA-TB, ypač vaistams atspari TB - YVA-TB, polirezistentiška TB), radiologinę formą (kavernos, abipusis pažeidimas, vienpusis pažeidimas). Išanalizavus tiriamųjų ligos istorijų dienynų įrašus, laboratorinius ir instrumentinius tyrimus, surinkti duomenys apie labiausiai tiketinus BDQ ir DLM šalutinius poveikius, vertintas jų pasiskirstymas bei ryšys su lytimi, amžiumi, alkoholio vartojimu. Naujai atsiradę tiriamųjų nusiskundimai buvo laikyti šalutiniais poveikiais, remiantis farmakologijos duomenu bazès British National Formulary (BNF) pateiktais duomenimis apie BDQ ir DLM bei kitų deriniuose vartojamų vaistų galimus šalutinius poveikius. Buvo vertinama, kuriam sunkumo lygiui pagal bendruosius nepageidaujamų reiškinių terminijos kriterijus (angl. Common Terminology Criteria for Adverse Events, CTCAE) priklauso rasti galimi šalutiniai poveikiai (1 lygis: lengviausi, minimaliai žalojantys arba visiškai nežalojantys sveikatos; 5 lygis: sunkiausi, sukeliantys mirtị). Kaip galimi naujųjų vaistų šalutiniai poveikiai buvo išskirti šie klinikiniai radiniai ir tiriamųjų skundai: pykinimas ir (arba) vėmimas, viduriavimas, išbèrimas, artralgija, neuropatija, širdies plakimo pojūtis, QTc intervalo prailgèjimas. Vertinant QTc intervalo prailgejjimą, buvo nustatyta, jog vyrų prailgèjęs QTc yra daugiau arba lygu $450 \mathrm{~ms}$, moterų - daugiau arba lygu $460 \mathrm{~ms}$ [7].

Duomenų analizė atlikta naudojant statistinę programą „IBM SPSS Statistics 24“. Galimų šalutinių poveikių pasireiškimo su amžiumi ryšiui nustatyti taikytas Stjudento (t) kriterijus. Galimų šalutinių poveikių ryšiui su lytimi bei alkoholio vartojimu nustatyti taikytas chi kvadrato $\left(\chi^{2}\right)$ testas. QTc prailgejimo gydymo metu ryšiui su lytimi nustatyti taikytas chi kvadrato $\left(\chi^{2}\right)$ testas. QTc prailgejjimo gydymo metu ryšiui su amžiumi nustatyti taikytas Stjudento (t) kriterijus.

\section{REZULTATAI}

Nuo 2016 m. antrojo pusmečio iki 2019 m. pirmojo ketvirčio pabaigos BDQ ir (arba) DLM buvo gydyti 32 pacientai. 21 (65,6 proc.) skirtas BDQ, devyniems (28,1 proc.) skirtas DLM, dviem (6,3 proc.) vienas po kito paskirti abu medikamentai (BDQ ir DLM). 26 (81,25 proc.) tiriamieji buvo vyrai, šešios $(18,75$ proc.) - moterys. Gydytų naujaisiais vaistais nuo TB pacientų amžius svyravo nuo 24 iki 66 metų. Tiriamųjų amžiaus vidurkis - 46 metai, amžiaus mediana - 50 metų. 13 (40,63 proc.) pacientų nevartojo alkoholio, o 19 (59,38 proc.) piktnaudžiavo alkoholiu. Nè vienas iš pacientų nebuvo užsikrètęs žmogaus imunodeficito virusu. Grupuojant pacientus pagal atsparumo vaistams formą, rasta, jog 11 pacientų (34,3 proc.) sirgo DVA-TB, 18 pacientų (56,3 proc.) sirgo YVA-TB, trims pacientams $(9,4$ proc.) nustatyta polirezistentine TB forma (1 pav.). Visi 32 pacientai sirgo plaučių VA$\mathrm{TB}$, nè vienas ekstrapulmoninès VA-TB atvejis šiuo laikotarpiu nebuvo gydytas BDQ ir (arba) DLM. Verti- 


\section{Moksliniai darbai ir apžvalgos}

nant tiriamųjų pasiskirstymą pagal radiologinę plaučių TB formą, pastebèta, kad radiologiniuose tyrimuose abipusis plaučių pažeidimas pasireiškè 22 (68,75 proc.) pacientams (iš jų trims rastos kavernos), o vienpusis pažeidimas - 10 (31,25 proc.) pacientų (2 pav.).

Deriniuose su BDQ ir (arba) DLM taip pat buvo skirti šie vaistai: etambutolis (ETB) - vienam (3,13 proc.) pacientui, FQ - septyniems (21,88 proc.), Cks - 27 (84,38 proc.), Cm - 15 (46,88 proc.), Km - vienam (3,13 proc.), LZD - 26 (81,25 proc.), pirazinamidas (Z) - 25 (78,13 proc.), protionamidas (Pt) - šešiems (18,75 proc.), rifampicinas $(\mathrm{R})-\operatorname{vienam}(3,13$ proc.), PASR - 26 pacientams (81,25 proc.).

16 (50 proc.) tiriamųjų gydymo BDQ arba DLM metu atsirado naujų skundų, kurie galètų būti laikomi BDQ ir DLM šalutiniais poveikiais.

Nustatyta, kad 13 (81,25 proc.) pacientų pasireiškè vienas galimas šalutinis poveikis, dviem (12,5 proc.) du galimi šalutiniai poveikiai, vienam (6,25 proc.) trys galimi šalutiniai poveikiai. Visiems 16 pacientu pasireiškę šalutiniai poveikiai laikyti kaip nežymiai trikdantys sveikatą ir neribojantys socialinio bei funkcinio aktyvumo ( 1 ir 2 sunkumo lygis pagal CTCAE). QTc intervalo prailgèjimas pasireiškè penkiems (15,63 proc.) pacientams. Iš jų du gydyti DLM, trys - BDQ. Dar dviem pacientams QTc intervalo prailgejjimas buvo rastas, prieš skiriant naujuosius prieštuberkuliozinius medikamentus. Šis EKG požymis išliko ir gydymo jais metu. Vienas tiriamasis, kuriam naujai registruotas QTc prailgèjimas gydymo BDQ metu, skundèsi atsiradusiu širdies plakimo pojūčiu, šio paciento QTc buvo $484 \mathrm{~ms}$. Dviem pacientams nustatytas QTc prailgejjimas $>500 \mathrm{~ms}$ (vienas ju gydytas BDQ, kitas - DLM). Vienam (3,13 proc.) tiriamajam buvo nutrauktas gydymas DLM dèl žymiai prailgejusio QTc intervalo (QTc reikšmè buvo 532 ms), EKG naujai atsiradus dešiniojo Hiso pluošto blokadai.

Kiti mažiau grèsmingi galimi šalutiniai poveikiai pasiskirstė taip: išbèrimas pasireiškè penkiems (15,63 proc.) pacientams (trys iš jų vartojo BDQ, du - DLM); pykinimas ir (arba) vèmimas - keturiems $(12,50$ proc.) pacientams (trys vartojo BDQ, vienas DLM); viduriavimas - vienam (3,13 proc.), vartojusiam BDQ; periferinè neuropatija pasireiškè trims (9,38 proc.) pacientams, iš kurių visi vartojo BDQ (3 pav.). Dèl nè vieno iš minètų šalutinių poveikių nebuvo nutrauktas gydymas BDQ arba DLM. Medicininiuose dokumentuose nurodyta, kad vienam (3,13 proc. visos imties) pacientui buvo nutrauktas gydymas BDQ dèl dusulio epizodų iš karto po medikamento pavartojimo (nesant alergijos arba anafilaksijos požymių), tačiau tokio galimo šalutinio poveikio prieinamuose informaciniuose šaltiniuose nenurodyta.

Ivertinus visų pacientams skirtų prieštuberkuliozinių medikamentų galimus šalutinius poveikius, manoma,

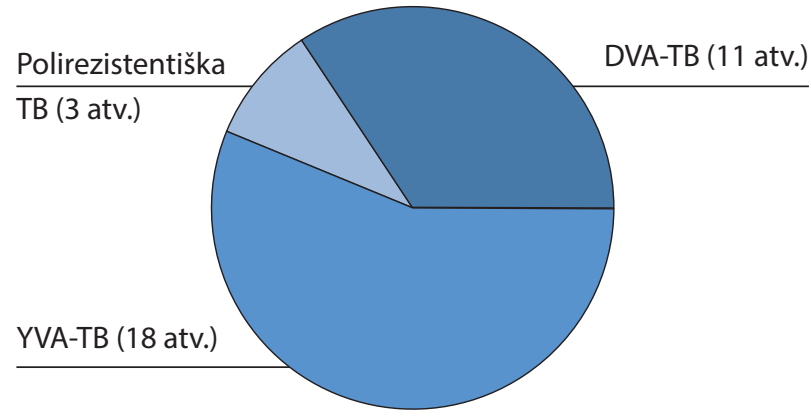

1 pav. Pacientų pasiskirstymas pagal TB atsparumo formas (nurodytas atvejų skaičius)

Santrumpos: DVA-TB - daugeliui vaistų atspari tuberkuliozė; YVA-TB - ypač vaistams atspari tuberkulioze; TB - tuberkulioze.

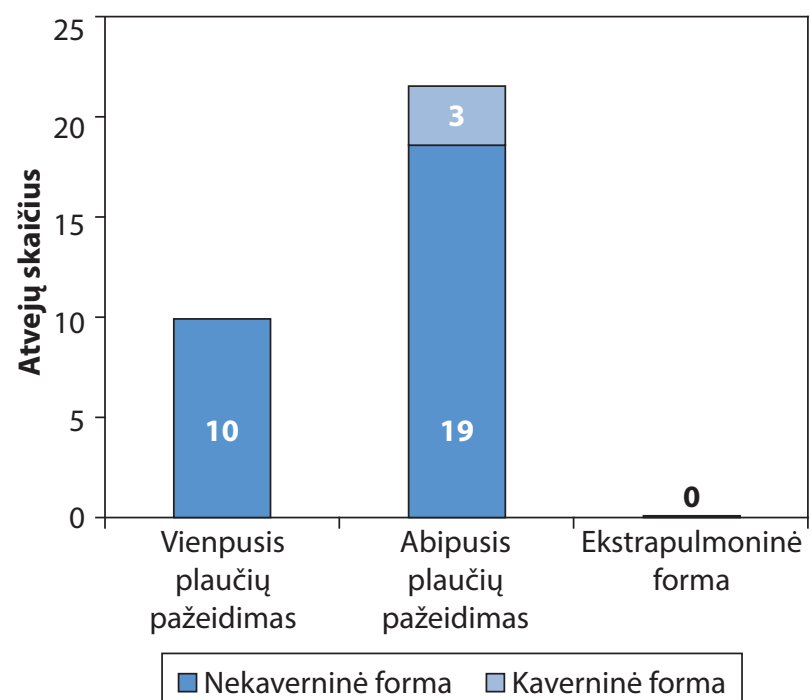

2 pav. Pacientų pasiskirstymas pagal radiologinị vaizdą (nurodytas atvejų skaičius)

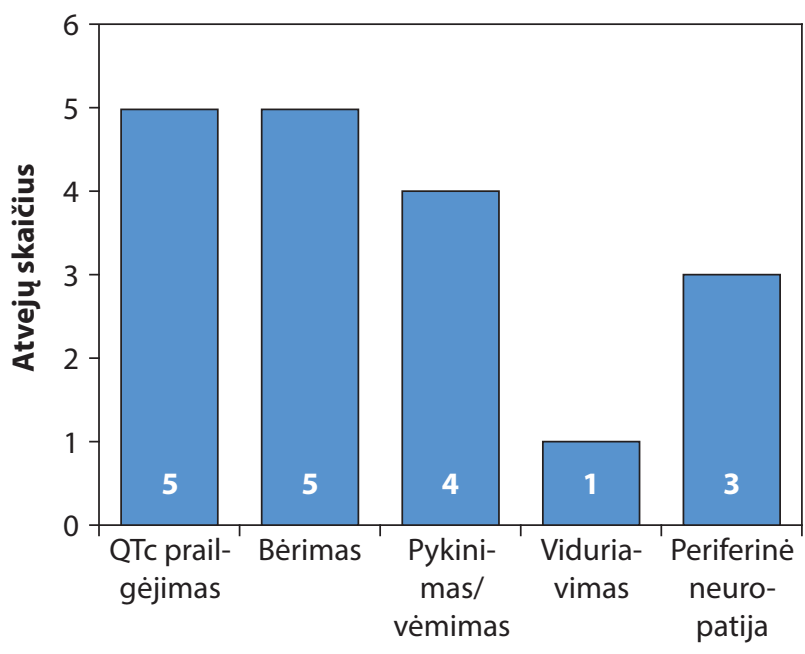

3 pav. Galimų šalutinių poveikių pasiskirstymas tiriamujų imtyje (nurodytas atvejų skaičius)

jog trimis atvejais (9,38 proc.) pasireiškusių šalutinių poveikių negalejo sukelti jokie kiti medikamentai (išskyrus BDQ arba DLM), visais šiais atvejais tai buvo QTc prailgejimas.

Pastebèta, jog apie nė vieną iš galimų šalutinių po- 


\section{Moksliniai darbai ir apžvalgos}

veikių nebuvo pranešta Valstybinei vaistų kontrolès tarnybai (VVKT).

Atliekant ši tyrimą, statistiškai reikšmingo ryšio tarp amžiaus, lyties bei alkoholio vartojimo ir galimų šalutinių poveikių pasireiškimo nenustatyta $(\mathrm{p}>0,05)$. Vis dèlto pastebèta, kad alkoholio vartojimo ryšys su galimų šalutinių poveikių pasireiškimu artimas statistiniam patikimumui $(\mathrm{p}=0,077)$, todèl daroma prielaida, jog statistiškai patikimų rezultatų būtų galima tikètis padidinus tiriamųjų imti. Statistiškai reikšmingo QTc intervalo prailgejjimo gydymo metu ryšio su amžiumi bei lytimi taip pat nepavyko nustatyti ( $p>0,05)$, tačiau pastebèta, jog šis simptomas tarp tiriamųjų pasireiškẻ tik vyrams.

\section{REZULTATU APTARIMAS}

Tyrimo metu dažniausiai rasti nežymiai sveikatą ir aktyvumą trikdantys šalutiniai poveikiai (asimptominis QTc prailgejjimas, išbèrimas, pykinimas, periferinė neuropatija), kitų autorių rezultatai panašūs - gydymo naujaisiais vaistais nuo TB metu dažniausiai dokumentuoti buvo virškinamojo trakto veiklos sutrikimai, periferinès neuropatijos, QTc intervalo prailgejimas [8,9]. Vis dèlto tiek užsienio autoriai, tiek mes pastebime, jog vertinti pasireiškusius simptomus kaip neabejotinus BDQ ir DLM šalutinius poveikius būtų klaidinga, žinant, jog TB nèra gydoma monoterapija.

Didesnio dèmesio vertas galimas BDQ ir DLM šalutinis poveikis yra QTc intervalo prailgèjimas, kuris gali sąlygoti gyvybei pavojingų širdies aritmijų atsiradimą. Vis dẻlto tiek šio tyrimo, tiek užsienio autorių tyrimų, kurių tiriamųjų imtys nuo 28 iki 428 pacientų, metu didelis QTc intervalo prailgèjimas (QTc>500 ms), gydant BDQ ir (arba) DLM, rastas nuo 0 iki 9,7 proc. pacientų, o vaisto nutraukimo atvejai dèl šios priežasties - pavieniai [2-3, 8-10]. Be to, kai kuriuose šaltiniuose nurodoma, jog pokyčius EKG galèjo sąlygoti ne tik BDQ arba DLM, bet ir kiti vaistai, ieinantys i gydymo schemą (PASR, moksifloksacinas, klofazaminas) [6]. Tai, mūsų manymu, yra gana svarūs rezultatai, pagrindžiantys naujųų vaistų nuo TB saugumą. Be to, QTc prailgejjimas panašiai pasiskirstè, nepaisant vaisto ir jo vartojimo būdo pasirinkimo (BDQ, DLM, BDQ ir DLM paeiliui arba kartu) [3, 8].

Atliekant ši tyrimą pastebèta, jog apie galimus vaistų nuo TB šalutinius poveikius VVKT neinformuojama, nepaisant to, jog ši praktika rekomenduojama tiek pačios VVKT, tiek vaistų gamintojų. Anksčiau minèto daugiacentrio tyrimo, kurio tiriamųjų imtis buvo 658 pacientai, metu nustatyta, kad įvairiose pasaulio šalyse gydytojai apie šalutinius vaisto poveikius savo šalies sveikatos kontrolès tarnybas informuoja retai iš tyrime dokumentuotų 57 sunkių šalutinių poveikių buvo pranešta apie tris (5,26 proc.), iš 447 lengvu šalutinių poveikių - apie 19 (4,3 proc.) [6].

\section{IŠVADOS}

Ivertinus šio tyrimo rezultatus, nustatyta, kad gyvybei pavojingi galimi šalutiniai poveikiai tarp pacientų, gydytų BDQ ir (arba) DLM, nepasireišké, todèl galima daryti išvadą, jog gydymas naujaisiais prieštuberkulioziniais vaistais yra pakankamai saugus. Siekiant atlikti sudėtingesnius statistinius skaičiavimus bei nustatyti papildomų veiksnių (lyties, amžiaus, alkoholio vartojimo) ịtaką galimų šalutinių poveikių pasireiškimui, tikslinga atlikti tyrimą su didesne tiriamujuc imtimi.

Gauta: 20200225

Priimta: 20200317

\section{LITERATŪRA}

1. WHO consolidated guidelines on drug-resistant tuberculosis treatment. Annexes 3-9. Geneva: World Health Organization; 2019 (WHO/CDS/TB/2013)

2. Borisov SE, Dheda K, Enwerem M, Romero Leyet R, D'Ambrosio L, Centis R, et al. Effectiveness and safety of bedaquiline containing regimens in the treatment of MDR- and XDR-TB: a multicentre study. Eur Respir J. 2017; 49(5):1700387.

3. Kim CT, Kim T-O, Shin H-J, Ko YC, Hun Choe Y, Kim HR, et al. Bedaquiline and delamanid for the treatment of multidrugresistant tuberculosis: a multicentre cohort study in Korea. Eur Respir J. 2018; 51(3):1702467.

4. Sarin R, Vohra V, Singla N, Singla R, Puri MM, Munjal SK, et al. Early efficacy and safety of Bedaquiline and Delamanid given together in a „Salvage Regimen “ for treatment of drug-resistant tuberculosis. Indian J Tuberc. 2019; 66(1):184-8

5. Joint Formulary Committee. British National Formulary. 2018. Available at: https://bnf.nice.org.uk

6. Borisov S, Danila E, Maryandyshev A, Dalcolmo M, Miliauskas S, Kuksa L, et al. Surveillance of adverse events in the treatment of drug-resistant tuberculosis: first global report. Eur Respir J. 2019; 54(6):1901522.

7. Rautaharju PM, Surawicz B, Gettes LS. AHA/ACCF/HRS recommendations for the standartization and interpretation of electrocardiogram. Part IV: the ST segment, T and U waves, and the QT interval. JACC Cardiovasc Imaging. 2009; 53(11):982-91.

8. Ferlazzo G, Mohr E, Laxmeshwar C, Hewison C, Hughes J, Jonckheere S, et al. Early safety and efficacy of the combination of bedaquiline and delamanid for the treatment of patients with drug-resistant tuberculosis in Armenia, India, and South Africa: a retrospective cohort study. Lacent Infect Dis. 2018; 18(5):536-44.

9. Olayanju O, Limberis J, Esmail A, Oelofse S, Gina P, Pietersen E, et al. Long-term bedaquiline-related treatment outcomes in patients with extensively drug-resistant tuberculosis from South Africa. Eur Respir J. 2018; 51(5). doi: 10.1183/13993003.005442018.

10. Guglielmetti L, Le Du D, Jachym M, Henry B, Martin D, Caumes E, et al. Compassionate use of bedaquiline for the treatment of multidrug resistant and extensively drug-resistant tuberculosis: interim analysis of a French cohort. Clin Infect Dis. 2015; 60(2):188-94. 